\title{
Business intelligence and big data in hospitality and tourism: a systematic literature review
}

Article

Accepted Version

Text

Mariani, M., Baggio, R., Fuchs, M. and Höpken, W. (2018) Business intelligence and big data in hospitality and tourism: a systematic literature review. International Journal of Contemporary Hospitality Management, 30 (12). pp. 35143554. ISSN 0959-6119 doi: https://doi.org/10.1108/IJCHM-072017-0461 Available at https://centaur.reading.ac.uk/76422/

It is advisable to refer to the publisher's version if you intend to cite from the work. See Guidance on citing.

To link to this article DOI: http://dx.doi.org/10.1108/IJCHM-07-2017-0461

Publisher: Emerald

All outputs in CentAUR are protected by Intellectual Property Rights law, including copyright law. Copyright and IPR is retained by the creators or other copyright holders. Terms and conditions for use of this material are defined in the End User Agreement.

www.reading.ac.uk/centaur 
Central Archive at the University of Reading

Reading's research outputs online 


\section{Business Intelligence and Big Data in Hospitality and Tourism: A Systematic Literature Review}

\section{Structured Abstract}

Purpose - This study examines the extent to which Business Intelligence and Big Data feature within academic research in hospitality and tourism published until 2016, by identifying research gaps and future developments and designing an agenda for future research.

Design/methodology/approach - The study consists of a systematic quantitative literature review of academic articles indexed on the Scopus and Web of Science databases. The articles were reviewed based on the following features: research topic; conceptual and theoretical characterization; sources of data; type of data and size; data collection methods; data analysis techniques; data reporting and visualization.

Findings - Findings indicate an increase in hospitality and tourism management literature applying analytical techniques to large quantities of data. However, this research field is fairly fragmented in scope and limited in methodologies and displays several gaps. A conceptual framework that helps to identify critical business problems and links the domains of Business Intelligence and Big Data to tourism and hospitality management and development is missing. Moreover, epistemological dilemmas and consequences for theory development of big datadriven knowledge are still a terra incognita. Last, despite calls for more integration of management and data science, cross-disciplinary collaborations with computer and data scientists are rather episodic and related to specific types of work and research.

Research limitations/implications - This work is based on academic articles published before 2017; hence, scientific outputs published after the moment of writing have not been included. A rich research agenda is designed.

Originality/value - This study contributes to explore in depth and systematically to what extent hospitality and tourism scholars are aware of and working intendedly on Business Intelligence and Big Data. To the best of our knowledge, it is the first systematic literature review within hospitality and tourism research dealing with Business Intelligence and Big Data.

Keywords: Big Data, Business Intelligence, systematic literature review, hospitality, tourism. Paper type: Literature review 


\section{Introduction}

In recent years, the notion of "Big Data" (BD) has become increasingly popular in both academic and non-academic media. The concept has generated a real buzz, especially on the Internet and social media. At the moment of writing the paper at hand (February 2017), a Google search using the circumlocution "Big Data" obtained more than 290 million resulting items. The circumlocution identifies the enormous volume of both unstructured and structured data generated by technology developments and the exponentially increasing adoption of devices allowing for automation and connection to the Internet. The use of networked devices, such as tablets and smartphones, has brought an explosion of data (Verhoef, et al., 2016), often in connection with user-generated content stemming from online social networks (Leung et al., 2013). Given their volume and characteristics, BD are difficult to process by deploying traditional statistical methods and software techniques (Chen et al., 2014). Nevertheless, BD is becoming rapidly popular as an emerging new field of inquiry also in social sciences, where it has been identified as an irreplaceable factor to enhance economic growth and prosperity and to solve societal problems (Mayer-Schönberger and Cukier, 2013) as well as a major driver for the creation of value for firms and customers (Verhoef, et al., 2016).

Methodologically, BD-based approaches allow researchers to overcome the difficulties of working with representative samples since BD virtually allows working with the entire population under scrutiny (Gerard et al., 2016). Supposedly, it enables to answer any question related to people's opinions, views, ideas and behaviours. At the same time, it seems to be a powerful tool to address novel research questions, to develop innovative research designs useful in the advancement of knowledge, ultimately generating both policy and managerial decision support (Gerard et al., 2016). On the one hand, there is consensus among business leaders and scholars, that BD represents a necessary condition to investigate today's complex business and social phenomena through the possibility of combining and recombining extremely different sources of information (Bedeley and Nemati, 2014). Similarly, firms leveraging BD can enhance their competitive advantage in a world were markets are global and huge amounts of information about consumers are available on the Internet (Verhoef et al., 2016). On the other hand, BD brings along a significant number of new challenges, risks and dilemmas, which have been explored and dealt with in a number of works (Boyd and Crawford, 2012; Fan et al., 2014; McFarland and McFarland, 2015; Ekbia et al., 2015; Gerard et al., 2016). Interestingly, scholars have addressed not only the challenges of data sharing and privacy, or new epistemological dilemmas, but also the challenges related to data extraction, collection, storage, processing, analysis, and visualization and reporting (Gerard et al., 2016). These processes all require specific resources and specialised skills, which will increasingly be juxtaposed to more established research methods (Kitchin and Lauriault, 2015). Despite the aforementioned challenges, there is broad consensus within both academic and business circles, that BD could make a difference as it captures real-time behaviours and opinions on virtually any aspect of human life (Chang et al., 2014; Power, 2014). For instance, in 2012, an IBMbased survey conducted on Chief Marketing Officers (CMOs) revealed that BD is considered a major business challenge (IBM, 2012). As such, Big Data have also started to be a significant source for Business Intelligence (BI) activities aimed at creating, delivering and capturing customer value (Verhoef et al, 2016).

BI and especially BI analytics have a longer tradition, but they constantly incorporate developments within data science in general and big data in particular, with the aim to enhance the return on investment and drive marketing decision-making (https://cmosurvey.org/results/). Consequently, both subjects are highly complementary. While the first known usage of the term BI dates back to 1865 (when the Banker Sir Henry Furnese had the ability to profit from his remarkable understanding of political and market issues and instabilities before his competitors (Devens and Miller, 2013)), the modern phase of BI dates back to the 1990ies. This first turning 
point in the development of Business Intelligence was characterized by tools specialized in extracting, transforming and loading data into a central data store. These tools could also organize, visualize and descriptively analyse data, such as doing online analytical processing (OLAP). However, these tools were developed with anyone but experts in mind, thus, most users were not capable of carrying out BI tasks on their own. The exponential growth of the Internet in the 21st century advanced this development and fully addressed the issues of complexity and speed. In particular, it addressed those issues through real-time solutions, cloudbased self-service options to improve data visualization as well as through advanced analytics and mobile-empowered BI platforms that integrated the end-user even more. BI is no longer an added utility, rather, it became a requirement for businesses looking to stay competitive, and even to remain afloat, in an entirely new, data-driven environment (Liebowitz, 2013).

The term Big Data (BD) appeared for the first time in Bryson et al.'s (1999) seminal paper published by the Communications of the ACM. Especially web 2.0 applications and the rise of mobile devices further increased data volumes. Thus, Big Data is not anymore an isolated phenomenon, but one that is part of a long evolution of capturing and using data, both for societal, scientific and business purposes. Big Data analytics is leading to better and more informed decision making for individuals and organizations, and, especially, creates value for stakeholders and customers (Verhoef et al., 2016).

Over the last decades, the fields of tourism, travel, hospitality and leisure have widely recognised the need for a customer-centric approach that primarily values tourists' needs, wants, preferences and requirements as major determinants in travel decisions in order to enhance both consumer satisfaction and the quality and memorability of the tourist experience (Correia et al., 2013; Prayag et al., 2013). Only very recently has an increasing amount of work related to the fields of Business Intelligence and Big Data grown to enrich these two lines of research. To the best of our knowledge, no review study has previously explored in depth to what extent hospitality and tourism scholars are aware of and working intendedly on Business Intelligence and Big Data. This is clear when observing that research on the role of BD and BI is still highly fragmented, and relegated to isolated research questions. To address this research gap, we conduct a systematic quantitative literature review on the concepts of Business Intelligence and Big Data and their application (and related techniques) in the fields of tourism and hospitality. To achieve this aim, our review is structured as follows: in section two, we provide a literature review of the wide field of big data and business intelligence. In section three, we illustrate the research methodology adopted to conduct the systematic literature review. Section four illustrates the major findings of the review and describes the articles by identifying research topics, conceptual and theoretical approaches, research designs, methods for data collection, analysis and reporting/visualization, data features such as sources of data, type of data and size. In section five, we identify theoretical and methodological knowledge gaps and development needs in travel, hospitality and tourism, as well as promising research areas for Big Data and Business Intelligence in hospitality and tourism. Finally, in section six we draw major conclusions and discuss the limitations of our review. 


\section{Business Intelligence and Big Data}

\subsection{Business Intelligence}

Business Intelligence (BI) comprises all the activities, applications and technologies needed for the collection, analysis and visualization of business data to support both operative and strategic decision-making (Dedić and Stanier, 2016; Kimbal and Ross, 2016). Currently, BI is used as an umbrella term to cover the domains of data warehousing, data mining and reporting as well as online analytical processing (OLAP) (Williams, 2016). Already in 1958, IBM researcher Hans Peter Luhn used the term Business Intelligence to highlight "the ability to apprehend the interrelationships of presented facts in such a way as to guide action towards a desired goal" (Luhn, 1958, p. 314). BI largely evolved from the 'decision support systems' (DSS) domain that emerged in the 1960s and developed throughout the mid-1980s. A DSS is defined as a computer-based information system that supports business or organizational decision-making activities that typically result in ranking, sorting, or choosing from among alternatives (Burstein and Holsapple, 2008; Sauter, 2011). Classic DSS applications usually comprise computer-aided models, data warehousing (DW), online analytical processing (OLAP), and executive information systems (Kimball et al., 2008). Only in 1989, later Gartner analyst Howard J. Dresner suggested that "business intelligence" is an umbrella term to describe "concepts and methods to improve business decision making by using fact-based support systems." (Power, 2007, p. 128).

Business Intelligence, as it is currently understood, offers historical, current and predictive views of business processes (Kimball et al., 2008). Typical functions embrace reporting, OLAP, analytics, data mining, business performance management, benchmarking, text mining, and prescriptive analytics (Rud, 2009; Williams, 2016). In particular, BI technologies show the capacity to handle large amounts of structured as well as unstructured data in order to help identify, develop or create new strategic business opportunities. Accordingly, enterprises apply BI to support a wide range of operational business decisions, such as product positioning or pricing. Moreover, BI provides strategic insights into new markets, supports the assessment of customer demand and the suitability of products and services developed for different market segments, or the impact of marketing and advertising strategies (Chugh and Grandhi, 2013). According to Kimball et al. (2008), BI is most effective when it combines external data derived from the customer markets in which a company operates with internal data stemming from company sources, such as financial or booking data. Thus, when matched, external and internal data provide the most complete picture, creating "intelligence" that cannot be derived from any singular set of data (Coker, 2014).

However, businesses should assess three critical areas before implementing a BI project (Kimball et al., 2008): 1) the level of commitment and sponsorship of the BI project from senior management; 2) the level of business needs for creating a BI implementation; and 3) the amount and quality of business data available. The latter requirement is an especially necessary condition, as without proper data (or with too low data quality) any implementation of a BI application will fail. Thus, data profiling, which aims at identifying the "content, structure and consistency of data" (ibid., 2008, p. 17), should happen as early as possible in the Business Intelligence cycle. A synthetic, though, complete representation of BI and its articulation is provided in Table 1, illustrating the major sub-components and fields related to Business Intelligence.

[Insert Table 1 about here] 


\subsection{Big Data}

Big Data (BD) has been portrayed as a contemporary hype (d'Amore et al., 2015). A few scholars have described it in view of its popularization as a kind of panacea, able to provide a wealth of useful insights into many aspects of the life of individuals, organisations and markets (Mayer-Schönberger and Cukier, 2013; McAfee et al., 2012). Other, more critical, scholars have depicted it as a cultural, technological, and scholarly phenomenon that rests on the interplay of technology, analysis and even mythology (Boyd and Crawford, 2012; Ekbia et al., 2015).

Big Data would not exist without technological development. Over the last three decades, the number of devices allowing for automation and/or connection to the Internet has increased exponentially. These devices have brought about a proliferation of data, often in connection with user-generated content stemming from online social networks (Leung et al., 2013), mostly accessible through a number of mechanisms and tools, such as Application Programming Interfaces (Russell, 2013, Mariani et al., 2016). This explosion in data availability has attracted the attention of computer and data scientists, whose efforts, beyond traditional methods of data management and warehousing, have been directed to novel techniques for big data analysis (Franks, 2012). Most techniques can be classified as "Machine Learning" (ML), a term commonly deployed to define the methods and algorithms used for mining data with the aim of extracting patterns, correlations and knowledge from apparently unstructured data sources (Witten et al., 2016). ML is undeniably gaining momentum as a set of processing techniques. Without going into details, it consists of learning algorithms discovering general rules or patterns in large data sets, filtering based on several variables, clustering large collection of objects into a small number of classes, et cetera (Mitchell, 1997). Whether supervised (i.e. outcomes come from training the algorithms with pre-labelled data) or unsupervised (i.e. algorithms derive outcomes from the data themselves), these techniques aim at giving a computer the ability to perform a task by using generalized approaches without being explicitly programmed for single tasks (for a more complete description see Witten et al., 2016).

It has been pointed out that big data displays a few main characteristics synthesized in the so-called "3Vs" (Chen et al., 2014; Laney, 2001). Accordingly, BD is characterized in terms of "volume" (i.e., it cannot be stored in an ordinary PC, as it typically exceeds billions of gigabytes), "variety" (i.e., data comes in a wide range of forms and shapes, such as texts, sounds, pictures, and videos and are often spatially and temporally referenced), and "velocity" (i.e., the speed at which data is created and modified is relevant). While the " $\mathrm{v"}$ " of volume has caught most of the attention of scholars so far, the remaining two aspects, variety and velocity, also make BD particularly interesting to address a number of practical issues and research questions. More recently, Baggio (2016) has detected further features related to BD. More concretely, four additional "Vs" are recognized. "Value" is relevant as big data help to create value for individuals and organizations and is becoming an object of economic transactions themselves. Secondly, "variability" plays a major role as it comes in the form of unstructured records whose meaning varies across contexts and times. Third, "veracity" is related to the reliability, validity and completeness dimension of the data. Fourth, visualization, namely the need to present the complexity of patterns in graphically understandable ways, is another important characteristic.

There are other features pertaining to Big Data. Often, whole populations, instead of samples, are gathered and empirically explored. This might lead to a reconsideration of statistical tools and inferential methods (Fan et al., 2014). These other features of BD include the following: the relational nature of variables that might be common across different sources; the flexibility needed when analysing the collections that might bring to scaling or easily extending variables and cases (Mayer-Schönberger and Cukier, 2013); the high probability to 
find a significant (but often spurious) correlation between any two series of data (Granville, 2013); and, finally, the high level of granularity, allowing to focus on specific features.

As far as technology is concerned, BD is often operated (when sizes are really big) through the Hadoop framework (White, 2015), which was generated in the form of an open source project of the Apache Software foundation, for both storage purposes and the distributed processing of datasets on clusters of commodity hardware. Distributed computing allows a virtually unlimited number of computers to process a significant amount of data simultaneously (in the order of petabytes, i.e. $10^{15}$ bytes). When it comes to the extraction of digital records, especially from third-party platforms, they can be retrieved quite easily through Application Programming Interfaces (APIs) that are freely accessible, for instance, for most social media platforms (e.g., Facebook, Twitter). They can be later processed through Artificial Intelligence (AI) methods, such as Machine Learning (ML) described above.

Leaving the technical aspects of BD (i.e. data retrieval, processing, analysis and visualization, respectively) aside, and going back to the characteristics of BD, their "value" is particularly relevant for business applications. Big Data can lead to better and more informed decision making for individuals and organizations and, thus, create value for stakeholders and customers (Verhoef et al., 2016). In other words, big data can be used for Business Intelligence (BI) purposes. More specifically, BD can empower BI, but it needs to be elaborated in a proper way. It remains that the risk of discovering deceptive outcomes and effects is quite high, especially if the quality of data and data pre-processing is low (Pyle, 1999; Lazer et al., 2014).

\subsection{The connection between Business Intelligence and Big Data in Hospitality and Tourism}

Any tourism company (be it a hotel or an airline) needs to leverage its managerial and marketing strategies, tactics, and tools to achieve and maintain sustained competitive advantage. This is more critical in the current highly dynamic economic environment where competition is fierce and consumers are demanding and experienced. Increasingly, it is evident that it is extremely difficult, even for well-established companies, to cultivate and sustain a competitive advantage for a long period. We are going through an age of "temporary advantage" and "hypercompetition" (D'Aveni, 1994; D'Aveni et al., 2010), where organizations need constant innovation to gain a temporary benefit and move ahead of the competition for a continued series of time periods (Mariani et al., 2016).

In this context, Big Data can make a difference for the BI of tourism companies, help them make better strategic and tactical decisions, and create value (Verhoef, 2016). This is the reason why $\mathrm{BD}$ is increasingly a crucial component of the wider BI umbrella (see section 2.1 and Table 1). However, research on the role of Big Data for Business Intelligence in the hospitality and tourism literature is still scant (d'Amore et al., 2015; Baggio, 2016) and highly fragmented. Single research activities often take place in a rather isolated manner and tackle a very specific aspect or research question without looking at the whole picture and embedding new work into the overall scholarly and practical context. Such research practices, however, are common during the emergence of new research areas or phenomena (Knudsen, 2003). Therefore, in the current phase of development of hospitality and tourism research leveraging $\mathrm{BD}$ and $\mathrm{BI}$, it is important and even overdue, to provide a clear overview of the different facets and issues of the wide research domain of BI and identify, discuss and integrate existing research activities leveraging BD into the overall context of the focal research domain. This is important in particular for two reasons. First, to stimulate but also to systematize further research activities. Second, to provide informational bases and overview on current application areas and utilization potentials for companies and stakeholders in the tourism domain. To achieve the above-mentioned goals and bridge this gap, we analyse state-of-the-art work done 
in Business Intelligence and Big Data in the domain of tourism and hospitality through a systematic literature review. In the next section, we explain the methodology adopted.

\section{Methodology}

In order to assess the extent to which Business Intelligence and Big Data feature within the hospitality and tourism literature, we carried out a systematic literature review of academic articles indexed on the Scopus and Web of Science databases. The method of systematic literature review has been largely adopted in the wider social sciences (see Tranfeld et al., 2003), including in the hospitality and tourism domain (see Gomezelj, 2016; Ip et al., 2011; Law et al., 2016). Thus, we embraced this approach to identify the relevant scientific work.

Subsequently, we have manually analysed and clustered refereed scientific articles into two major groups (i.e. BI-related and BD-related), and explored them in detail based on the following features:

- research topic;

- conceptual and theoretical characterization;

- sources of data;

- type of data and size;

- data collection methods;

- data analysis techniques;

- data reporting and visualization.

The identification of the aforementioned features and clusters is done to help us identify theoretical and methodological knowledge gaps, development needs and promising research areas for both Business Intelligence and Big Data in the hospitality and tourism domain.

\subsection{Data}

As mentioned, the present study retrieved data from two large databases: Scopus and Web of Science. The main reason for having selected the two aforementioned databases is that they are considered to be the most comprehensive sources of scholarly articles and academic work in the social sciences (Vieira and Gomes, 2009). More precisely, Scopus covers more than 22,000 titles from over 5,000 international publishers, and therefore it is considered one of the most comprehensive repository of the world's research output across a wide range of academic disciplines. On a similar scale, Web of Science provides access to seven databases that reference cross-disciplinary research covering over 28,000 journals. To these sources, we juxtapose the digital library of the International Federation for Information Technologies, Travel and Tourism (http://www.ifitt.org/resources/digital-library/) that indexes 992 academic publications from the Journal of Information Technology and Tourism and the proceedings of the Enter conferences. Overall, the use of these databases ensures the reliability, validity and timeliness of the articles retrieved (Law et al., 2016; Gomezelj, 2016). Data used for this study was collected from January to March 2017, while the search was confined to the period of 20002016.

We adopted several search criteria. First, only full-length empirical and review/policy articles were included. Second, other articles, such as conference papers and book chapters, were excluded. Third, only empirical studies were considered in this study. Thereafter, the authors carefully read each selected article based on the aforementioned criteria and, thus, determined whether the article could be included in the analysis or not. We used different sets 
of keywords to build the target populations and samples. First, we searched the keywords "Business Intelligence" and "Big Data" on both databases. Second, we narrowed down our target population to look for work related to the hospitality and tourism areas by leveraging the following searches: 1) matching "Business Intelligence" with the keywords "Hospitality" and "Tourism" separately and, similarly, 2) matching "Big Data" with the keywords "Hospitality" and "Tourism" separately. A search using the keyword "Business Intelligence" in conjunction with other keywords representing Business Intelligence components (such as "data warehouse", "data mining", etc.) in the titles, abstracts and keywords returned 70,212 and 42,158 academic publications on Scopus and Web of Science, respectively over the period of 2000-2016. Apparently, there is a wide distribution over time and a linear and relevant growth over the last 16 years for Scopus-indexed works (Fig. 1). The situation is significantly different for articles indexed in WOS, with low numbers (less than 10 articles per year), due to the lower coverage than Scopus.

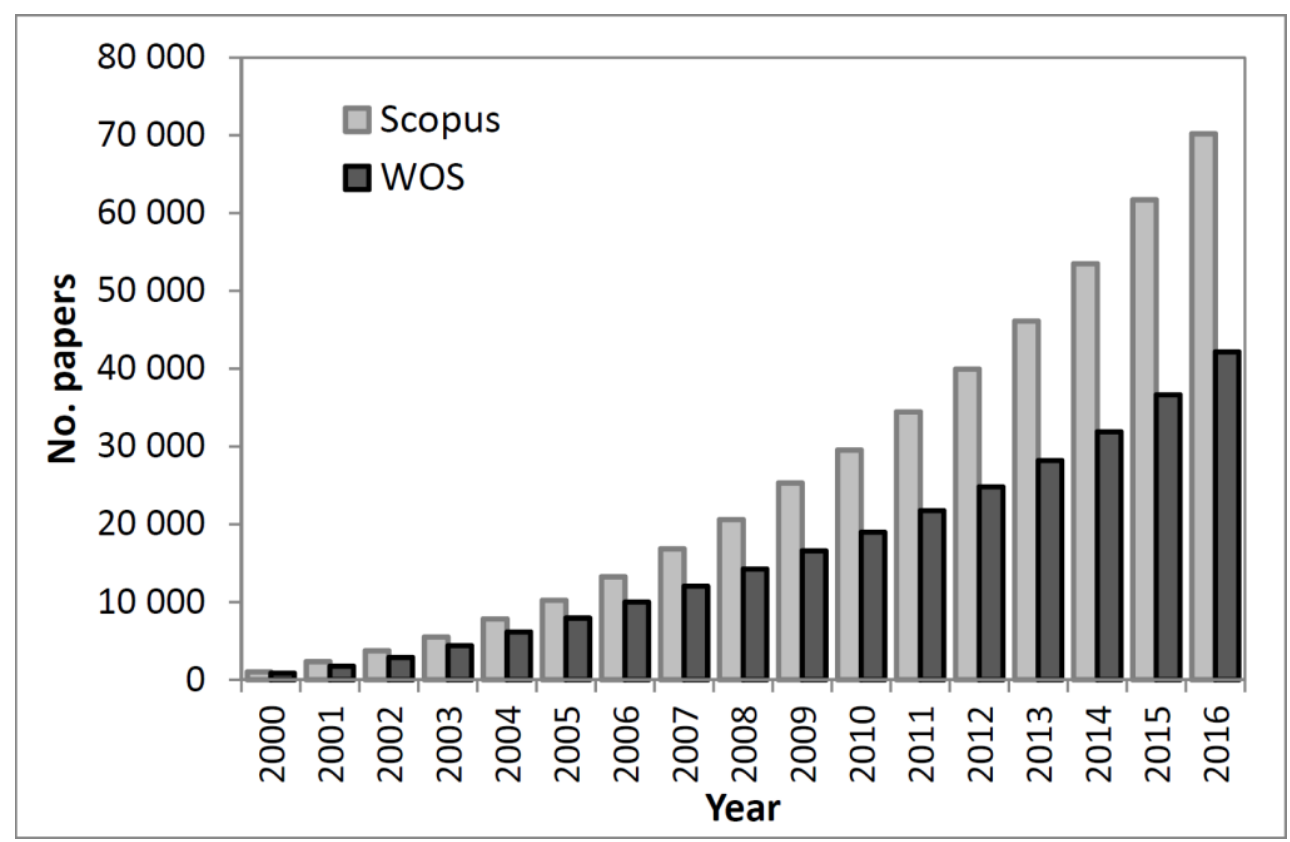

Fig. 1 Cumulative time distribution of Business Intelligence works published over the last 16 years in Scopus and Web of Science (WOS).

A slightly different situation appears when focusing on Big Data. A search using the keyword "Big Data" in the titles, abstracts and keywords returned 29,101 and 18,159 academic publications on Scopus and Web of Science respectively over the period of 2000-2016. The time distribution is largely uneven and testifies to the very recent growth of interest in the topic. A look at Fig. 2 shows an almost exponential growth, with an acceleration during the last five years. 


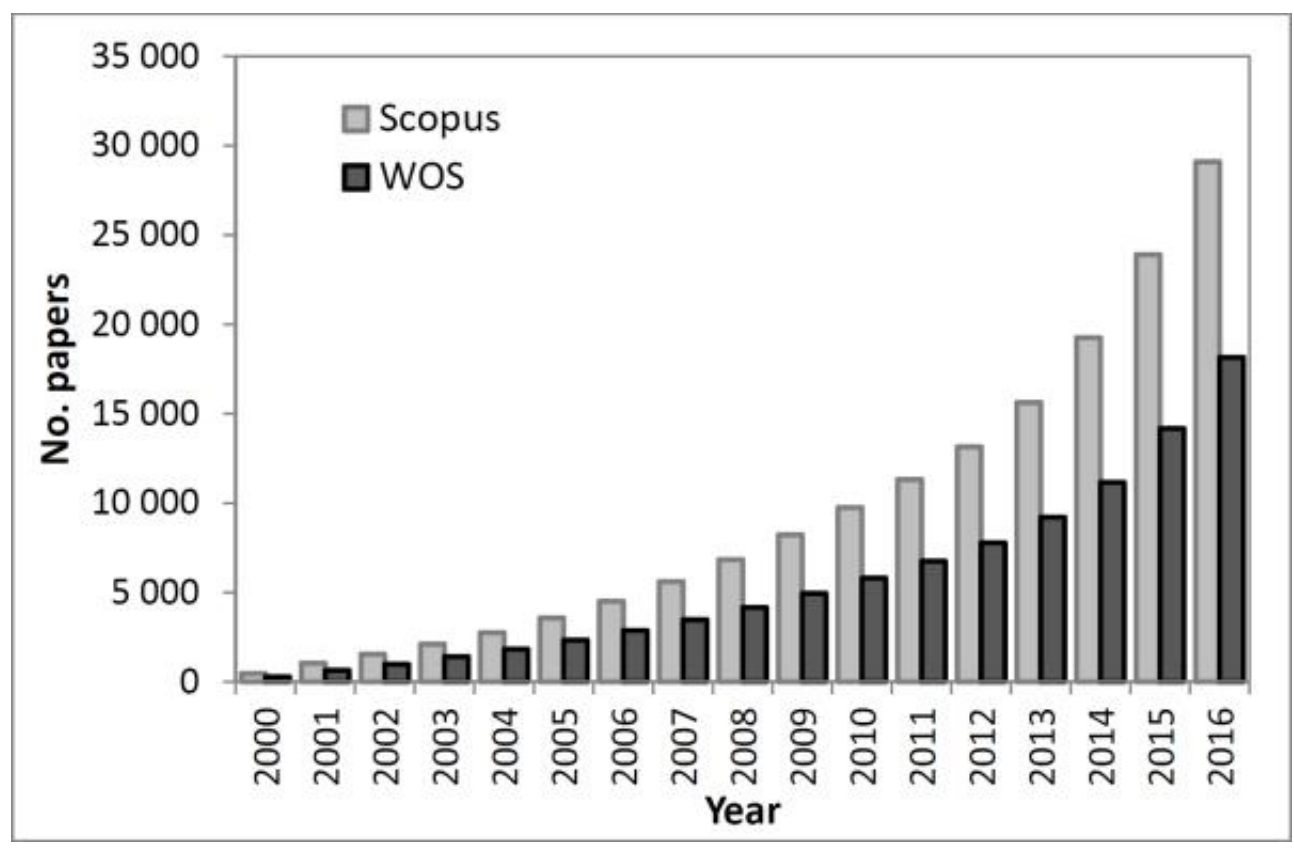

Fig. 2 Cumulative time distribution of Big Data works published over the last 16 years in Scopus and Web of Science (WOS)

Finally, we refined our search in order to ensure the direct relevance of the selected academic works to the wide area of tourism and hospitality. We have, therefore, constrained our search on publications including "travel, tourism, tourist, hospitality or leisure" in their titles, abstracts and keywords. Titles and abstracts have been manually inspected to further select work actually dealing with BI and BD. The consensus of multiple experienced researchers based in different academic institutions and countries and with dissimilar research and cultural backgrounds and skills is thought to have minimized any potential personal bias during this last step of the selection process. The final data set, after checking for titles that were present in both databases (duplications), includes 77 articles related to BI and 96 articles related to Big Data. The final sample does not include duplicated articles. As mentioned, in the following section, we review the sample of articles, based on the following features: research topic; conceptual and theoretical characterization; sources of data; type of data and size; data collection methods; data analysis techniques; data reporting and visualization.

\section{Results and Discussion}

The total number of BD articles in the area of tourism and hospitality selected as described above is 96. The number of BI publications is 77. Their time distribution is given in Fig. 3 (for the last five years). Incredibly, it seems that besides the hype about the BD issue, not many hospitality and tourism researchers have decided to pay some effort in studying these topics so far, and only a handful of them have invested time and resources in considering the possibilities of an application of Big Data to the tourism and hospitality field. 


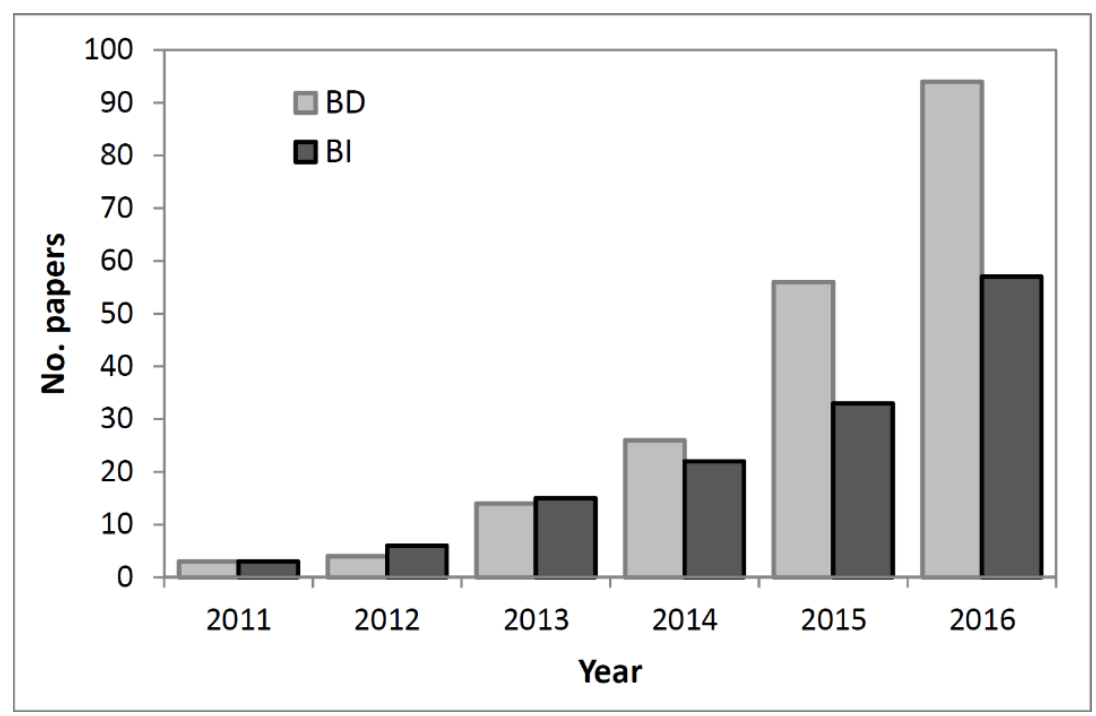

Fig. 3 Cumulative time distribution of BD and BI tourism and hospitality related works for the last five years (base year is 2011)

What is more interesting is the fact that only 17 of these BD articles appear in tourism or hospitality journals, and, therefore, are more accessible to the tourism academic community. The same situation is found for the BI articles: only nine are available in tourism journals. All the others are found in computer science (mainly), transportation, marketing management or geography journals. In what follows, we describe the main features of a selection of articles whose topics are closely related to the domains of hospitality and tourism. These publications have appeared in both hospitality and tourism outlets and other scientific journals, mainly in the areas of computer science, transportation, marketing management and geography.

\subsection{A critical discussion on the articles dealing with Business Intelligence}

A selected number of BI articles with their main characteristics are reported in Table 2.

\section{[Insert Table 2 about here]}

The recurring terms in the titles and abstracts are summarised in the word cloud of Fig. 4. A word cloud is the visual representation of the frequency with which words are found in a given context, providing a perceivable image of the most prominent terms and related themes (i.e. higher frequency of a term equals larger size). Here, most of the words are rather generic and show that the subject area has been treated through a relatively traditional approach. 


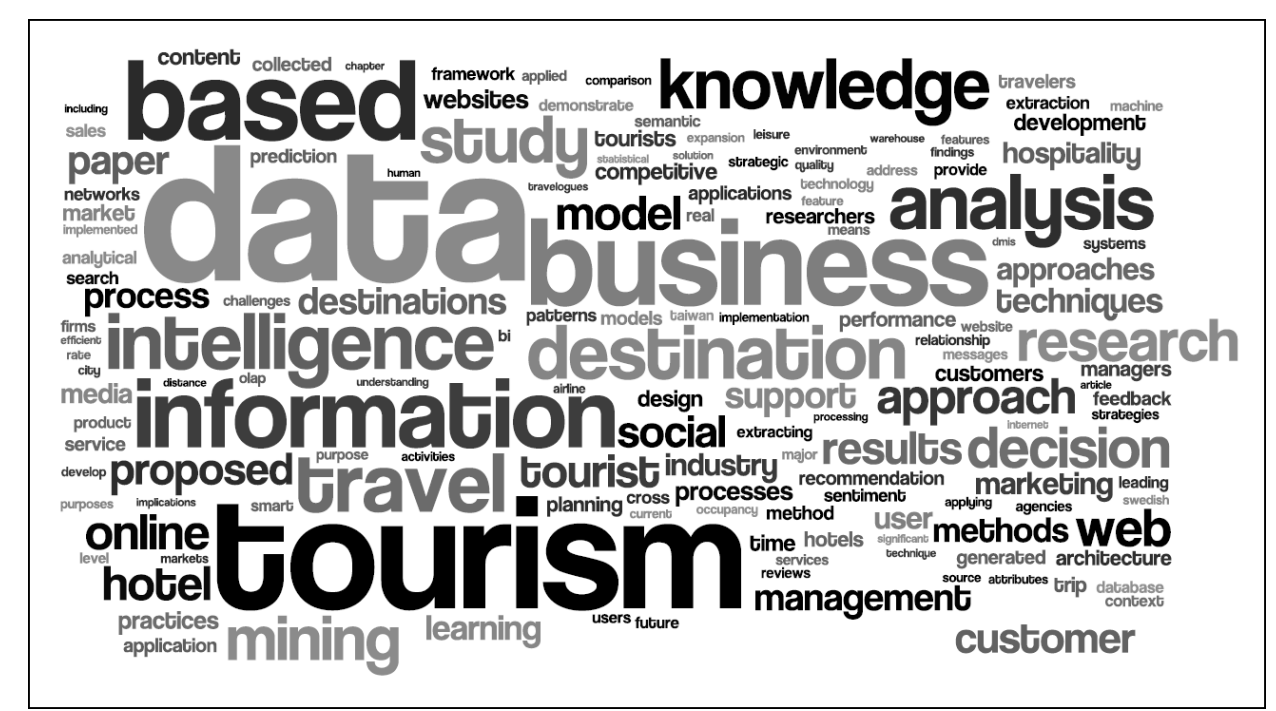

Fig. 4 Word cloud with the most used terms in the BI papers selected

The "tourism" BI literature focuses mainly on themes such as the organisation of destination marketing information systems (Ritchie and Ritchie, 2002), methods for the analysis of specific tourists' segments (Barbieri and Sotomayor, 2013), the examination of competitive intelligence practices in the hospitality sector (Köseoglu et al., 2016), and frameworks for managing and analysing data (Fuchs et al., 2013; Höpken et al., 2015). Interestingly, among the most recent tourism BI publications, four (actually 22\%) are also catalogued in the BD listings (Fuchs et al., 2014; Lam and McKercher, 2013; Marine-Roig and Anton Clavé, 2015; Qiao et al., 2014). This is a clear indication of the fact that tourism scholars (at least those few who treat these topics) have well understood the capability of BD to provide insights that are useful for enriching the business intelligence practices of destinations and tourism and hospitality operators.

From the 77 originally identified BI articles, 31 of them were selected for further investigation and critical discussion. These articles were selected since they deal with topics related to the domain of Business Intelligence (see table 2). First, only one article is purely conceptual by its nature. In this article, Pope et al (2009) conceptualize the challenges and analytical opportunities found in collecting large volumes of data from airline websites and travel agencies. All other identified publications use either structured (i.e. sixteen papers), unstructured (i.e. six papers), or both types of data (i.e. eight papers). Second, two papers are conducting research about Business Intelligence in the hospitality and tourism domain. More precisely, Ritchie and Ritchie (2002) analyze survey data in order to assess tourism industry stakeholders' knowledge, needs and current use of research results and tools in the area of business intelligence. Similarly, in a more recent publication, Köseoglu et al. (2016) evaluate awareness and knowledge about competitive intelligence in the hotel industry. Interestingly, the authors find that the most crucial competitive intelligence activities include price comparisons as well as the analysis of user-generated content (Köseoglu et al., 2016). The remaining 28 papers apply BI-based methods, such as descriptive analytics (e.g. OLAP) or artificial intelligence methods (i.e. machine learning), in order to gain new and relevant knowledge in the tourism and hospitality domain. Concerning topic diversity, we can conclude that the analyzed research papers are covering a wide topical spectrum. More concretely, topical coverage ranges from the market-share estimation of automobile and air transportation (Ashiabor et al., 2007), the analysis of customers' searching behavior of airline tickets (Holland et al., 2016), location selection decisions (Chen and Tsai, 2016), to BI-based customer value analysis (Hsieh, 2009) and BI-based recommendation expert system for travel agencies and 
tourism intermediaries (Hsieh, 2011). Kisilevich et al. (2013) propose a BI-based tool that assists travel intermediaries to acquire strategic information about hotels, such as room rates and location characteristics, in order to leverage profitable deals. Likewise, while the work by $\mathrm{Lu}$ and Zhang (2015) applies machine-learning techniques, such as decision trees and meta learning, to estimate trip purposes for long-distance passenger travel, Tseng and Won (2016) propose a sales force support system using business intelligence methods, such as explorative data analysis and data mining (e.g. sequential pattern discovery). Snavely et al. (2008) present a set of algorithms for 3D modelling of the world's most photographed sites, cities, and landscapes based on Internet imagery. Additionally, we also found several relevant topics typically associated with the current use of Business Intelligence, such as opinion aggregation from user-generated content (Carrasco et al. 2013; Rossetti et al. 2016) and feature extraction from online reviews (Li et al., 2015; Sànchez-Franco et al., 2016). The latter is sourced either from general social media platforms, such as Facebook (Kwok and Yu, 2016), or from travel blogs and online travel reviews (Marine-Roig and Anton Clavé, 2015). Finally, we identified the publications of Fuchs et al. $(2013 ; 2014)$ and Höpken et al. (2015), who both apply Business Intelligence methods in the context of a Destination Management Information System prototypically implemented for Swedish destinations. While in Fuchs et al. (2013) OnlineAnalytical Processing (OLAP) is employed to identify the proportion of tourists with the smallest ecological footprint, Höpken et al. (2015) apply a multi-dimensional data warehouse model to offer a novel approach for BI-based cross-process knowledge extraction for tourism destinations.

From a methodological perspective, the $27 \mathrm{BI}$ articles identified in the hospitality and tourism domains apply a broad spectrum of BI techniques: First, descriptive analytics are found in Carrasco et al. (2013), Fuchs et al. (2013; 2014), Höpken et al. (2015), and Tseng and Won (2016). However, the work by Höpken et al. (2015) also applies data mining techniques, such as Decision Trees and Association Rule Mining.

When it comes to the aggregation and (sentiment) analysis of user-generated content, Rossetti et al. (2016) apply both K-Nearest Neighbor User Based (KNN-UB), K-Nearest Neighbor Item Based (KNN-IB) and Probabilistic Matrix Factorization (PMF) techniques. By contrast, Marine-Roig and Anton Clavé (2015) use parsing and categorizations through a wordfrequency-based Site Content Analyzer. Moreover, in order to analyze user-generated content, Fuchs et al. (2014) employ machine learning techniques, like Support Vector Machines (SVM), Naïve Bayes (NB) and K-Nearest Neighbor (KNN). The work by Kwok and Yu (2016) combines machine learning and human intelligence to analyze Facebook messages initiated by hospitality companies. More precisely, the authors use Support Vector Machines (SVM) to classify Facebook messages as for instance "popular/less popular" and different message types, to identify relevant keywords to define a taxonomy of Facebook messages (Kwok \& Yu, 2016). Moreover, some authors use Latent Dirichlet Allocation (LDA) topic models to analyze online reviews from TripAdvisor (Amadio \& Procaccino, 2016) and web content in conjunction with web server log file data of a tourism DMO platform (Arbelaitz et al., 2013). The article by Li et al. (2015) applies feature extraction by frequent keywords and Emerging Pattern Mining (EPM) techniques for identifying emergent hotel features based on 118,000 online reviews from TripAdvisor. In a similar vein of analysis, Sànches-Franco et al. (2016) extract features from hotel reviews by using pathfinder network scaling (PNS), principal component analysis (PCA) and linear mixed-effects regression. Finally, Zhu et al. (2016) apply Gazetteer-based location detection and semantic correlation detection by natural language parsing techniques to extract location information from travelogues.

Artificial Neural Networks (ANN) are employed in the form of self-organizing feature maps as a means of clustering large amounts of data (Hsieh, 2009; Dursun \& Caber 2016), or in the form of back-propagation networks (Hsieh, 2011; Zhang \& Huang, 2015) and multilayer 
perceptrons (Kisilevich et al., 2013) as classification techniques. Moreover, the article by Chen and Tsai (2016) applies rough set theory (RST) to support customers' location decisions in the context of a restaurant chain.

Finally, the BI papers identified in the hospitality and tourism domain also comprise (multi-variate) statistical techniques, such as Multi-dimensional Scaling (MDS) (ibid et al., 2013), mixed logit models (Ashiabor et al., 2007; Solnet et al., 2016), or mathematical modelling (Holland et al., 2016). When it comes to 3D modelling from Internet imagery of photographed sites (Snavely et al., 2008), very specialized techniques, such as SIFT key-point detectors, approximate nearest neighbors and $k d$-tree analysis is applied. Similarly, Kisilevich et al. (2013) apply highly specialized techniques, such as Voronoi Tessellation Partitioning, additive regression with isotonic regression, Locally Weighted Learning, as well as LibSVM nu-SVR.

Concerning data collection methods, twelve articles feature a one-time manual approach, while nine others feature an automated periodical approach for collecting data. Four papers display a combination of both methods for data collection. When it comes to visualization of BI-based knowledge, eight articles feature dashboards and/or Online Analytical Processing (OLAP) (Kisilevich et al., 2013). Ashiabor et al. (2007) develop special visualization forms, such as market share plots. Likewise, Snavely et al. (2008) reconstruct scenes and photo connectivity graphs for eleven well-photographed sites.

To conclude, in relation to research type and topic, data source and structure, data collection methods as well as data analysis and visualization techniques, the discussed BI papers show a broad variety and, by that, clearly demonstrate the diversity and multi-faceted dimensions of the domain of business intelligence. In numbers, while ten of the 31 analyzed publications that deal with BI applications relate to tourism destinations (i.e. local, regional or national tourism organization, destination management organization), eleven are linked to hospitality businesses. Similarly, nine papers can be assigned to tourism and travel industries (i.e. five BI studies relate to travel agencies and four to the airline business). Finally, only one BI study identified by our review has been conducted in the field of leisure. Nevertheless, all analyzed papers on BI applications in travel, tourism and hospitality clearly underpin the huge potential for future applications of business intelligence in this domain.

\subsection{A critical discussion on the articles dealing with Big Data}

A selected number of BD articles with their main characteristics are reported in Table 3.

[Insert Table 3 about here] 
A detailed reading of the tourism abstracts highlights some other interesting facts.

The first thing to notice, for what concerns Big Data, is that the abstracts and titles contain rather generic terms, with no or little reference to the specific terminology often used in works about Big Data (see Fig. 5).

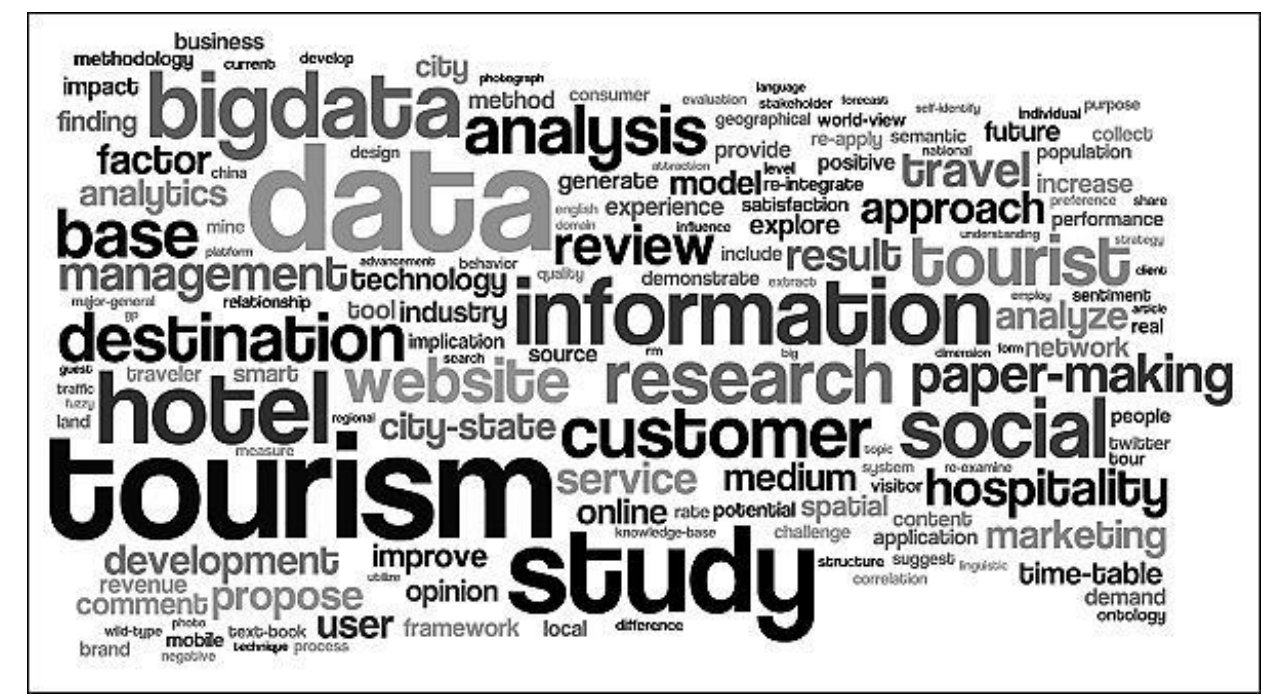

Fig. 5 Word cloud with the most used terms in the BD papers selected

Some articles feature a rather general and somewhat conceptual discussion about Big Data or about the general importance of using Big Data for improving and extending present research activities (Buhalis and Foerste, 2015; Dolnicar and Ring, 2014; Wang et al., 2015). Despite the call for a better integration between official statistics and Big Data (see e.g. Heerschap et al., 2014; Lam and McKercher, 2013), not many of the identified publications attempt to find a solution. For instance, Yang et al. (2014) use web traffic volume data of a destination marketing organisation to predict hotel demand, showing an improvement in the error reduction in contrast to more traditional forecasting models. Similarly, Önder et al. (2014) use Flickr geotagged photos to assess the presence of tourists in Austria, showing that the method provides more reliable outcomes for cities than at a regional level. Finally, Fuchs et al. (2014) demonstrate how BD analytics can be beneficial for BI practices in a tourism destination and propose an architectural solution that combines different sources of data, such as customers' web search, booking and feedback data.

Advanced approaches, such as Machine Learning techniques, artificial intelligence or Bayesian classification methods are practically ignored, and the most used technique is a simple statistical textual analysis of pieces collected online from which the authors derive a number of insights (see e.g. Berezina et al., 2016 or Lu and Stepchenkova, 2015). A notable exception are the papers by Menner et al. (2016) and Schmunk et al. (2014) that perform sentiment analysis on a large corpus of user generated contents by employing advanced techniques, such as support vector machines, naïve Bayes classifiers, and latent semantic indexing.

Not many other articles actually use online sources. An exception is the article of Xiang et al. (2015). The authors analyse a large corpus of tourists' reviews to derive a number of interesting considerations about hotel guest experience and its association with satisfaction ratings (Xiang et al., 2015). Similarly, Marine-Roig and Anton Clavé (2015) collect a large quantity of user-generated comments (i.e., travel blogs and online travel reviews) concerning the area of Barcelona and deduce the perceived image of the city through these reports. Along this line, Park et al. (2015) analyse tweets generated by cruise travellers showing their main interests and preferences, thus, providing useful suggestions for feasible marketing strategies. Mariani et al. (2016) examine Facebook pages of Italian destinations revealing how destinations use the social platform and which posts' characteristics have 
the biggest impact for actively engaging visitors. Finally, d'Amore et al. (2015) present a hard- and software system for helping in the troublesome collection of data from online social media platforms. Other types of records are even more sparingly used. Examples are: Kasahara et al. (2015), who study GPS tracks and a possible method for inferring transportation modes, or Gong et al. (2016), who use taxi trajectory data (GPS-based) for guessing the probability of points of interest to be visited in a city, thus, deducing possible trip purposes and travel patterns. It must be noted that all these publications use relatively small quantities of data (in the range of a few dozen thousand records) compared with what would be (probably) available for the studies. Only a few publications, in fact, employ relatively large quantities (typically of more than one million records) for their analyses. Examples of publications using such large quantities of data include studies of geotagged photos from online providers (Paldino et al., 2015; Wood et al., 2013), tweets containing geographical location data (Mocanu et al., 2013), or large databases (Supak et al., 2015). These studies provide a good assessment of the statistical and geographical distributions of both local people and visitors, thus giving a better picture of the extension of the phenomenon on the areas examined and of tourists' preferences in terms of most visited or appreciated locations or points of interest.

Two specific papers are worth mentioning here. One is the study of global mobility of people conducted by Hawelka et al. (2014) who geotagged one year worth of tweets (almost one billion), deriving patterns and some characteristics of the movements of international travellers. The second is the report by Roca Salvatella (2014) who collected mobile phone traffic and credit card transactions data in Madrid and Barcelona for one month (about 700,000 phones and 170,000 cards), retrieving information about a number of detailed activities and expenditures of international visitors to the two cities. While 25 of the 96 analyzed articles using BD applications are related to tourism destinations (i.e. local, regional or national tourism organization, destination management organization), 22 are linked to hospitality businesses. Similarly, 48 articles can be assigned to the travel industry. Finally, only one study identified by our review has been conducted in the field of leisure. Clearly, in cases where an article addressed both hospitality and destination aspects, such as with Yang et al. (2014), we had to make a choice on how to categorize it to avoid duplications; the criterion adopted was based on the prevalence of a theme over the other. Overall, the analyzed papers leveraging on BD in travel, tourism and hospitality clearly underpin the huge potential for future applications of BD with and increasing use of BD stemming from online consumer reviews in the hospitality sector.

\section{Reflections and Conclusions}

\subsection{Conclusions}

The systematic literature review reveals that there is an increase in hospitality and tourism management literature applying analytical techniques to large quantities of data. However, this research field is fairly fragmented in scope and limited in methodologies and displays several gaps. A conceptual framework that would help identify critical business problems and link the domains of Business Intelligence and Big Data to tourism and hospitality management and development is missing. Moreover, epistemological dilemmas and consequences for theory development of big datadriven knowledge are still a terra incognita.

Before we introduce the theoretical and practical implications of our review, we briefly sketch a number of domain-independent challenges stemming from the implementation of a BI and BD environment (Jannach, 2016, p. 109). Here, we must also remark that there is a quite strong interplay between $\mathrm{BI}$ and $\mathrm{BD}$. After all, data is the underlying resource for $\mathrm{BI}$, and the relationships existing between the two are often so close that it is difficult to separate them, as already noted here and in other publications (Fan et al., 2015; Lycett, 2013). BD has emerged as a disruptive technology with effects that will surely be reshaping BI, a domain completely relying on data analytics for the purpose of better decision-making. 
In our survey, one important point concerns questions of how to collect automatically data represented in non-standardized formats, and where to store these huge volumes of data for later processing. In addition, combining different heterogeneous data sources is puzzling, as issues of data integration and data quality arise if data comes from sources both inside and outside the organization. Probably, the most difficult question is how to extract 'useful' knowledge from data in order to support better decision making. For instance, richer data visualizations (e.g. through customizable dashboards) might be appropriate in one case, while for other cases more sophisticated prescriptive machine learning models might be more suitable for knowledge extraction. Finally, existing business models need to be adapted based on new insights gained from BI and BD. This similarly challenging task requires out-of-the-box thinking as well as cross-departmental work. Furthermore, it will require that academic and research institutions set up collaborations and synergies with industry stakeholders to get access to previously non-accessible data (Klein and Jacobs, 2016).

In recent years, more and more data has become available through the extensive use of online applications, data that is increasingly used for the analysis of consumer behaviours, the elaboration of marketing strategies, predicting trends, detecting frauds, and for producing new, faster and more detailed statistics (Gandomi and Haider, 2015). The latter point is of utmost importance for the hospitality and tourism domains as most diagnostics and predictive tourism activities are based on official records provided by national or local statistical organizations, or are based on surveys conducted in 'traditional' ways. However, the reliability of official tourism data has been questioned several times in the literature (see for instance, Lam and McKercher, 2013). The reasons behind this questioning include the poor harmonization of data collection methods, the currency of data, and statistical estimation procedures. Even more important is the issue that, with the growth of multiple forms of travels and stays, many visitors go unobserved (Baggio, 2016). Thus, one possible solution to improve data quality is resorting to the records of innumerable trails that millions of individuals leave online when using the many currently available technological platforms (Baggio, 2016). Indeed, electronic footprints have shown to be a valuable source to assess travellers' and tourists' behaviour and related decision making and knowledge sharing (Lu and Stepchenkova, 2015).

However, the attempt to apply knowledge created in real-time on the base of tourists' on-site behaviour is especially challenging since, currently, Business Intelligence applications are still a rarity in tourism (Fuchs et al., 2014; Höpken et al., 2015; Yuan and Ho, 2015). Consequently, realtime knowledge generation in the hospitality and tourism domain needs to be significantly improved through ubiquitous (i.e. mobile) end-user applications (Kolas et al., 2015), showing the capacity to collect tourists' real-time feedback (Kolas et al., 2015) and to trace movement patterns most effectively (Shoval and Isaacson, 2010; Zanker et al., 2010; Höpken et al., 2012). Supplier-based knowledge sources from the digital destination eco-system (Baggio and Del Chiappa, 2014) can also be integrated in real-time, such as through product-profiles and available information automatically extracted from supplier websites and databases. Thus, real-time knowledge about suppliers' service potential (property status), the complementarity of destination offers and its evaluation through tourists' real-time feedback, all significantly support dynamic need fulfilment in a collaborative tourism destination environment (Fuchs et al., 2016). To conclude, BD is mainly a collection of data generated from people, companies, groups, and networks, implying that international and cultural differences still have a dominant influence (Klein and Jacobs, 2016). This, however, makes consolidation and interpretation of data, as well as their patterns and correlations on various aggregation levels, a highly complex and difficult task.

\subsection{Theoretical implications and research needs}

Though some researchers are already claiming 'the end of theory' as the 'data deluge makes the scientific method obsolete' (Andersson, 2008), there is still a strong need for theories addressing the consolidation and interpretation of data. More precisely, it is only a 'theory', which is capable to deduce conclusions from (i.e. causal) patterns in data in a self-consistent way (Han, 2015). From an 
epistemological perspective, without theories, BD merely creates (algorithmically) generated numbers totally uncoupled from social realities. According to the German philosopher Hegel (1830), all the reasonable is conclusion. Thus, theories are and will always be required as the "narrative way" behind knowledge generation. From this perspective, Anderson's (2008) claim of the 'end of theory' would imply the end of mind (Han, 2015). Hence, mixed-method approaches, triangulation and sense making through various theoretical frameworks are still helpful to understand the broad landscape of big data. Moreover, BD might be complemented and combined with small data stemming from traditional data collection and analysis techniques, a reflection of what is happening right now (Kitchin and Lauriault, 2015), also in light of the difficulties that small and medium firms can face in equipping themselves with the right human resources, skills and capabilities (Coleman et al., 2016). Obviously, theories are constantly revised and new concepts (e.g. long tail) developed in light of new empirical evidence. For instance, by referring to the above sketched example on mobile customer relationship management in a tourism destination context (Kolas et al., 2015), theories on consumer (i.e. tourist) behaviour help defining (i.e. modelling) the relevant tourism domain (e.g. tourists' decision-making during a stay in a typical winter destination). By doing so, the relevance of major data sources can be assessed. Thus, only those customer-based data will be collected (e.g. in realtime) which have an expected influence on desirable, ideally sustainable, consumer behaviour (Fuchs et al., 2014; Höpken et al., 2015). In addition, this leads to a systematic avoidance of a data overload.

Certainly, there are several knowledge-gaps and development needs in the domain of Business Intelligence and Big Data in hospitality and tourism. As far as knowledge gaps are concerned, by referring to the relative share of $\mathrm{BD}$ and $\mathrm{BI}$ articles falling into the tourism and hospitality domains, one can conclude that tourism scholars are increasingly aware about the significance and potential impact of BD and BI on these business and societal domains. Nevertheless, the absolute number of articles published during the period under analysis was marginal. Thus, future work is needed to conceptualize and (e.g. prototypically) implement innovative BI solutions as well as to critically assess the use and usefulness of these BI applications and BD in the tourism and hospitality domains. Secondly, we lack a conceptual framework that helps to identify critical business problems in the hospitality and tourism domain (Xiang 2016, p. 127). For example, the linkages between data analytics and smart tourism development are yet to be established (Gretzel et al., 2015). Third, and related to the previous point, several issues related to $\mathrm{BD}$, such as the epistemological dilemmas and consequences for theory development of data-driven knowledge, are still a terra incognita (Ekbia et al., 2015). Fourth, more attention should be paid to issues problematizing critically the use of BD stemming from online platforms as a data source (Mariani and Borghi, 2018). For instance, to date most of the studies relying on online travel review platforms have not dug in depth about the differences in the way data is produced, frequently neglecting an accurate process of data understanding and data cleaning. Fifth, as discussed above, at the destination level, methodological work is needed to complement official statistics that keep their basic validity with the large quantity of data available online (Fan et al., 2014; Kitchin and Lauriault, 2015). At the individual firm level, an important challenge will be to complement small data (SD), collected through traditional methodologies (such as traditional customer surveys), with big data stemming from online records. Thus, we envision that companies in hospitality and tourism will keep on conducting ad hoc traditional customer surveys, but at the same time should (and will) juxtapose the perception metrics stemming from SD with the actual behavioural data stemming from BD generated from online records (Heerschap et al., 2014). In other words, the "variety" feature characterising BD should be applied to data tout court, regardless of its source (e.g., traditional customer surveys vs. online review platforms). Bringing BD and SD together might enrich the managerial insights of destination and hospitality marketers as SD typically relate to customer perceptions, while BD have the advantage of including also behavioural analytics. Last, it seems that while management and tourism management scholars are becoming increasingly aware of the relevance of BD for BI, still their collaborations with computer and data scientists are rather episodic and related to specific types of work and research. However, there is a need to integrate progressively management and data science (Gerard et al., 2016) 
in a more systematic way through the creation of multi- and inter-disciplinary research teams involving hospitality and tourism management scholars on the one hand and computer and data scientists on the other hand (Fuchs et al., 2014; Höpken et al., 2015). This might ensure that a diverse set of competences, capabilities and skills will be used to face a range of complex research issues with the right analytical tools.

\subsection{Practical implications}

After the identification of robust and validated methodologies, the development of hardware infrastructures and open software applications (Alaei et al., 2017; Kirilenko et al., 2017; Höpken et al., 2017; Dergiades et al., 2018) could provide researchers and practitioners with adequate tools for dealing with Big Data in tourism and hospitality settings. As highlighted, real-time Business Intelligence delivers information about business processes as they occur. The inherent automated analysis capacity enables the initiation of corrective actions and the adjustment of business rules, in order to optimize business processes in real-time. One example would be mobile customer relationship management (m-CRM) applications, which automatically detect customer opportunities immediately communicated to customers' smartphones. Thus, a promising task for Business Intelligence in hospitality and tourism is to create such real-time data, which is currently unavailable, in order to reflect tourists' on-site behaviour by means of ubiquitous (mobile) e-CRM applications (Sinisalo et al., 2007; Vogt, 2011; Wang et al., 2012; Kolas et al., 2015). On the base of this new type of customer data, valuable knowledge for businesses and destination management can emerge through methods of real-time business intelligence and data mining. Finally, real-time knowledge needs can be used to adapt intelligent ubiquitous (mobile) customer applications, thereby enhancing the match between customer needs and offered destination products. For instance, real-time travel patterns, characterized by ad-hoc and less systematic travel decisions and activities, can be considered in activity-based transportation models and recommender systems (Hermans and Liu, 2016). For this purpose, the use of mobile phone data and credit-card data offers valuable insights into travellers' activities and travel behaviour in real-time (Liu et al., 2013). The aforementioned trends are evolving fast and future developments in the wider field of artificial intelligence applied to data mining and predictive learning look quite promising to enhance the intelligence capabilities of tourism and hospitality organizations and assist them in understanding fast changing and hypercompetitive markets that can translate into sustained business growth.

We can summarize and better highlight these practical implications as follows. First and foremost, top management teams in large hospitality firms (such as hotel chains listed on stock exchanges) and in other large corporations operating in travel and tourism (such as airline companies) need to be supported by good data analysts familiar with the latest developments of data science (Davenport and Patil, 2012). Small and medium sized hospitality and tourism enterprises that are not able to hire data scientists, could purchase reports generated by consulting companies working on big data analytics, or find a way to collaborate and form groups to generate the critical mass needed to assemble the necessary resources for these activities. Second, more fluid communication flows should connect managers in charge of strategic decision making with data analysts/scientists, especially if the latter ones are not "vertically specialized" in the hospitality and tourism sector. The choice of relevant data sources, suitable collection methods and data cleaning/validation and understanding techniques will stem from a fruitful dialogue between those knowledgeable of the distinctive features of the business operations (i.e., the managers) and the data analysts/scientists. Third, and related to the previous point, right now - apart from a few hospitality and tourism scholars pioneering BD there are no vertically specialized data analysts, with the exception of a handful of companies (e.g., STR Global in hospitality) that develop "analytics" in a rather traditional way based on competitive performance measures shared by company managers. There is, therefore, a huge opportunity even for those companies to involve data scientists interested in hospitality and tourism. On the other hand, there is a huge opportunity for educational institutions to revise and rejuvenate their programs in the 
field by dedicating resources to educate on the issues of BD and BI. Fourth, digital business models in tourism and hospitality are being developed at the speed of light through corporate entrepreneurship initiatives (see the incubators and accelerators of such companies as Travelport in the digital distribution domain); certainly those companies could capitalize even more on BDinformed products and services that might improve their competitiveness and performance.

\subsection{Limitations and future research}

This research is not without limitations. First, from the observed overall trends related to the scientific production related to BI (Fig.1) and BD (Fig.2), it is apparent that these two areas of research are gaining increasing scientific attention. Therefore, we expect that at the moment of writing our work, other articles are being produced and published at a very fast pace and, thus, cannot be accommodated in this review. Second, as usually done (Gomezelj, 2016; Law et al, 2016), we have used the two main literature databases: Scopus and Web of Science. These, although collecting a large number of journals and scientific publications, and probably all the most important ones, still cannot be considered complete, also considering the process that takes for these repositories to index new publications. Finally, we had to simplify and reduce most of the technical details typically used in the $\mathrm{BI}$ and BD fields to make the article accessible to a wide social science audience. This decision, while making our work more manageable, has prevented us from going deeper into many features and technical aspects related to the fields scrutinised; such details might allow us to further enrich our research agenda.

Besides limitations, this systematic literature review has allowed us to identify several main themes and issues that might contribute to shape future research agendas for BD and BI in hospitality and tourism. Although quite popular and strongly pushed by many, there is still a notion that Big Data is largely overlooked by the majority of researchers in the field. The same seems to happen for what concerns Business Intelligence studies. It is difficult to understand fully the reasons for this situation, yet we interpret them as follows. First, there seem to exist a cultural gap between hospitality and tourism researchers who should be ready to embrace, accept, and implement, novel research methods. This needs to pass, for many, through a steep learning curve. Moreover, refinements and revisions of methodological approaches are needed, especially in terms of the combination of "old" and "new" data. Time will be needed to legitimise and sustain the aforementioned data-driven methods in the hospitality and tourism scientific community (Xiang, 2018; Shoval et al., 2018). Second, and related to the previous point, scholars willing to make robust contributions to BI and BD in hospitality and tourism in the future should make sure to:

- choose suitable data sources (e.g. social media, online payment and credit card transactions, mobile phone traffic, e-Commerce transactions and booking engines, etc.);

- collect and store data on a large scale, making use of appropriate data management techniques, ranging from traditional data warehouse structures to more flexible an agile data lakes;

- clean and validate data, taking into account volatility, replicability, privacy, overlaps and redundancies;

- extract meaningful knowledge from large data volumes (by also considering suitable theoretical frameworks) in real-time, if necessary, and with an emphasis on multi- and omnichannel behaviours;

- combine different data sources for deriving complete, valid and reliable outcomes at different levels (individual, firm, business network, industry);

- use content spontaneously generated by Internet and web-users to gain additional knowledge on travellers' beliefs, behaviours, and preferences in order to overcome limitations of traditional survey-based research methods.

Third, BD and BI educational programmes and units for hospitality and tourism management have been largely missing. Therefore, academic institutions and schools should introduce, support and 
develop them by means of specific investments. This will be relevant to bridge a cultural gap preventing the next generation of managers to make sense of BD for BI purposes (Coleman et al., 2016). Progress in tourism and hospitality research will be possible only by coaching researchers to be able to address the needs of tourism companies in a data-led economy. Fourth, the resources (hardware and software) needed to actually treat huge quantities of data are not easily available to hospitality and tourism researchers, but rather sit in computer science departments (Ekbia et al., 2015). Moreover, many of the modern analysis techniques require a good knowledge of some computer programming language or database management system that are not very popular among the scholars in the tourism field. Similarly, for BI good practices call for well and rationally designed, organised and managed information systems. To overcome these issues, it is necessary for hospitality and tourism scholars to set up inter- and multi-disciplinary collaborations and research teams with an inclusive attitude towards computer and data scientists. Last, given the issues of privacy related to retrievable data for research purposes that could be either public or confidential and proprietary, academic and research institutions have to initiate, build and leverage strong partnerships and collaborations with industry and institutional stakeholders.

\section{References}

Alaei, A.R., Becken, S. and Stantic, B. (2017), "Sentiment analysis in tourism: Capitalizing on big data”. Journal of Travel Research, doi 10.1177/0047287517747753

Amadio W.J. and Procaccino J.D. (2016), "Competitive analysis of online reviews using exploratory text mining”. Tourism and Hospitality Management, Vol. 22 No.2, pp. 193-210.

Andersson, C. (2008), "The end of theory: the data deluge makes the scientific method obsolete", Wired Magazine, Vol. 16 No. 7, pp. 1-3.

Arbelaitz O., Gurrutxaga I., Lojo A., Muguerza J., Pérez J.M., and Perona I. (2013), Web usage and content mining to extract knowledge for modelling the users of the Bidasoa Turismo website, Expert Systems with Applications, Vol. 40 No.18, pp. 7478-7491.

Ashiabor, S., Baik, H., and Trani, A. (2007), "Logit models for forecasting nationwide intercity travel demand in the United States", Transportation Research Record, Vol. 2007, pp. 1-12.

Baggio, R. and Del Chiappa, G. (2014), "Real and virtual relationships in tourism digital ecosystems", Information Technology and Tourism, Vol. 14 No. 1, pp. 3-19.

Baggio, R. (2016), "Improving Tourism Statistics: Merging official records with Big Data", in Fuchs, M., Höpken, W. and Lexhagen (Eds.), Big Data and Business Intelligence in the Travel and Tourism Industry. Östersund, Mid Sweden University, pp. 89-92.

Barbieri, C. and Sotomayor, S. (2013), "Surf travel behavior and destination preferences: An application of the Serious Leisure Inventory and Measure", Tourism Management, Vol. 35, pp. 111-121.

Bedeley, R. and Nemati, H. (2014), "Big Data Analytics: A Key Capability for Competitive Advantage", paper presented at the 20th Americas Conference on Information Systems (AMCIS), 7-9 August, Savannah, GA. Berezina, K., Bilgihan, A., Cobanoglu, C., \& Okumus, F. (2016). "Understanding satisfied and dissatisfied hotel customers: text mining of online hotel reviews", Journal of Hospitality Marketing \& Management, Vo. 25, pp. 1-24.

Boyd, D. and Crawford, K. (2012), "Critical questions for big data: Provocations for a cultural, technological, and scholarly phenomenon”, Information, Communication and Society, Vol. 15 No. 5, pp. 662-679.

Buhalis, D. and Foerste, M. (2015), "SoCoMo marketing for travel and tourism: Empowering cocreation of value", Journal of Destination Marketing and Management, Vol. 4 No. 3, pp. 151-161.

Burstein, F. and Holsapple, C.W. (2008), Handbook on Decision Support Systems. New York: Springer. 
Bryson, S., Kenwright, D., Cox, M., Ellsworth, D. and Haimes, R. (1999), "Visually exploring gigabyte datasets in real time", Communications of the ACM, Vol. 42 No. 8, pp. 83-90.

Carrasco, R.A., Muñoz-Leiva, F., and Hornos, M.J. (2013), "A multidimensional data model using the fuzzy model based on the semantic translation", Information Systems Frontiers, Vol. 15 No. 3, pp. 351-370.

Carter, P. L. (2016), "Where are the enslaved?: Tripadvisor and the narrative landscapes of southern plantation museums", Journal of Heritage Tourism, Vol.11 No.3, pp. 235-249

Chang, R. M., Kauffman, R. J., and Kwon, Y. (2014), "Understanding the paradigm shift to computational social science in the presence of big data", Decision Support Systems, Vol. 63, pp. 67-80.

Chen, L. F., and Tsai, C. T. (2016). „Data mining framework based on rough set theory to improve location selection decisions: A case study of a restaurant chain", Tourism Management, Vol. 53, pp. 197-206.

Chen, M., Mao, S., and Liu, Y. (2014), "Big data: A survey", Mobile Networks and Applications, Vol. 19 No. 2, pp. 171-209.

Chiang W.-Y. (2015), "Applying data mining with a new model on customer relationship management systems: A case of airline industry in Taiwan", Transportation Letters, Vol. 6 No. 2, pp. 89-97.

Coleman, S., Göb, R., Manco, G., Pievatolo, A., Tort-Martorell, X., and Seabra Reis, M. (2016), "How can SMEs benefit from Big Data? Challenes and path forward", Quality and Reliabiltiy Engineering Interantional, Vol. 32, pp. 2151-2164.

Correia, A., Kozak, M., and Ferradeira, J. (2013), "From tourist motivations to tourist satisfaction. International", Journal of Culture, Tourism and Hospitality Research, Vol. 7 No. 4, pp. 411-424.

Chugh, R. and Grandhi, S. (2013), "Why business intelligence? Significance of business intelligence tools and integrating BI governance with corporate governance", International Journal of EEntrepreneurship and Innovation, Vol. 4 No. 2, pp. 1-14.

Coker, F. (2014). Pulse: Understanding the Vital Signs of Your Business, Bellevue, WA: Ambient Light Publishing.

d'Amore, M., Baggio, R., and Valdani, E. (2015), "A practical approach to big data in tourism: a low cost Raspberry Pi cluster". In I. Tussyadiah and A. Inversini (Eds.), Information and Communication Technologies in Tourism 2015 (Proceedings of the International Conference in Lugano, Switzerland, February 3-6), Berlin, Springer, pp. 169-181.

D'Aveni, R.A., Dagnino, G.B., and Smith, K.G. (2010), "The Age of Temporary Advantage", Strategic Management Journal, Vol. 31 No. 13, pp. 1371-1385.

D'Aveni R.A. (1994), Hyper competition: Managing the Dynamics of Strategic Maneuvering, New York, Free Press.

Davenport, T.H., and Patil, D.J. (2012), “Data Scientist: the Sexiest Job of the 21st Century," Harvard Business Review Vol. 90 No. 10, pp. 70-76.

Dedić N. and Stanier C. (2016), "Measuring the success of changes to existing business intelligence solutions to improve business intelligence reporting", Lecture Notes in Business Information Processing, Springer International Publishing, Vol. 268, pp. 225-236.

Dergiades, Th., Mavragani, E., and Pan, B. (2018). “Google Trends and tourists' arrivals: Emerging biases and proposed corrections, Tourism Management, Vol. 66, pp. 108-120.

Devens, R.M. and Miller, R. (2013), Encyclopaedia of commercial and business anecdotes, Vol. 1, New Yor, Hard Press Publishing.

Dolnicar, S. and Ring, A. (2014), “Tourism marketing research: Past, present and future", Annals of Tourism Research, Vol. 47, pp. 31-47.

Dursun A., and Caber M. (2016), "Using data mining techniques for profiling profitable hotel customers: An application of RFM analysis." Tourism Management Perspectives, Vol. 18, pp.153-160. 
Ekbia, H., Mattioli, M., Arave G., Ghazinejad, A., Bowman, T., Suri, V., Tsou, A., Weingart, S. and Sugimoto, C.R. (2015), "Big data, bigger dilemmas: A critical review", Journal of the Association of Information Science and Technology, Vol. 66 No. 8, pp. 1523-1545.

Erl, Th., Khattak, W. and Buhler, P. (2015), Big Data Fundamentals - Concepts, Drivers and Techniques, New York, Prentice Hall.

Fan, S., Lau, R. Y., and Zhao, J. L. (2015), "Demystifying big data analytics for business intelligence through the lens of marketing mix", Big Data Research, Vol. 2 No. 1, pp. 28-32.

Fan, J., Han, F., and Liu, H. (2014), "Challenges of Big Data analysis", National Science Review, Vol. 1 No. 2, pp. 293-314.

Franks, B. (2012), Teaming the Big Data Tidal Wave: Finding Opportunities in Huge Data Streams with Advanced Analytics, John Wiley and Sons.

Fuchs, M., Höpken, W. and Lexhagen, M. (2016), "Dynamic Need Fulfilment in a Collaborative Destination Environment”, in Fuchs, M. Höpken, W. and Lexhagen (Eds.), Big Data and Business Intelligence in the Travel and Tourism Industry, Mid Sweden University, Östersund, pp. 97-100.

Fuchs, M., Abadzhiev, A., Svensson, B., Höpken, W., and Lexhagen, M. (2013), "A knowledge destination framework for tourism sustainability: A business intelligence application from Sweden", Tourism: An Interdisciplinary Journal, Vol. 61 No. 2, pp. 121-148.

Fuchs, M., Höpken, W., and Lexhagen, M. (2014), "Big data analytics for knowledge generation in tourism destinations - A case from Sweden", Journal of Destination Marketing and Management, Vol. 3 No. 4, pp. 198-209.

Gandomi, A., and Haider, M. (2015), "Beyond the hype: Big data concepts, methods, and analytics", International Journal of Information Management, Vol. 35 No. 2, pp. 137-144.

García-Pablos, A., Cuadros, M., \& Linaza, M. T. (2016), "Automatic analysis of textual hotel reviews", Information Technology and Tourism, Vol. 16 No. 1, pp. 45-69.

Gerard, G., Osinga, E.C., Lavie, D., and Scott, B.A. (2016), "Big data and data science methods for management research", Academy of Management Journal, Vol. 59 No. 5, pp. 1493-1507.

Gomezelj, D.O. (2016), "A systematic review of research on innovation in hospitality and tourism", International Journal of Contemporary Hospitality Management, Vol. 28 No. 3, pp. 516 - 558.

Gong, L., Liu, X., Wu, L., and Liu, Y. (2016), "Inferring trip purposes and uncovering travel patterns from taxi trajectory data", Cartography and Geographic Information Science, Vol. 43 No. 2, pp. 103-114.

Granville, V. (2013), "The curse of big data". Retrieved June, 2015, from http://www.analyticbridge.com/profiles/blogs/the-curse-of-big-data.

Gretzel, U., Sigala, M., Xiang, Z., and Koo, C. (2015), "Smart tourism: foundations and developments", Electronic Markets, Vol. 25 No. 3, pp. 179-188.

Gunter, U., Önder, I. (2016), "Forecasting city arrivals with google analytics“, Annals of Tourism Research, Vol. 61, pp. 199-212.

Han, Byung-Chul (2015), Psychopolitik - Neoliberalismus und die neuen Machttechniken, Fischer, Frankfurt a.M.

Hawelka, B., Sitko, I., Beinat, E., Sobolevsky, S., Kazakopoulos, P., and Ratti, C. (2014), "Geolocated Twitter as proxy for global mobility patterns", Cartography and Geographic Information Science, Vol. 41 No. 3, pp. 260-271.

He, J., Liu, H., and Xiong, H. (2016), "SocoTraveler: Travel-package recommendations leveraging social influence of different relationship types", Information and Management, Vol. 53 No. 8, pp. 934-950.

Heerschap, N., Ortega, S., Priem, A., and Offermans, M. (2014), Innovation of tourism statistics through the use of new big data sources, Paper presented at the 12th Global Forum on Tourism Statistics, 15-16 May 2014, Prague, Czech Republic, Retrieved July 2014 from http://www.tsf2014prague.cz/assets/downloads/Paper\%201.2_Nicolaes\%20Heerschap_NL.pdf.

Hegel, G.W.F. (1830), Enzyklopädie der philosophischen Wissenschaften im Grundrisse - Die Wissenschaft der Logik, Frankfurt a. M. 
Hermans, E. and Liu, F. (2016), "Using and combining promising data types in transportation models", in Fuchs, M. Höpken, W. and Lexhagen (2016) (eds.), Big Data and Business Intelligence in the Travel and Tourism Industry, Mid Sweden University, Östersund, pp. 101-103.

Holland, C.P., Jacobs, J.A. and Klein, S. (2016), ,The role and impact of comparison websites on the consumer search process in the US and German airline markets", Information Technology and Tourism, Vol. 16 No. 1, pp. 127-148.

Höpken, W., Deubele, Ph, Höll, G., Kuppe, J., Schorpp, D., Licones, R. and Fuchs, M. (2012), "Digitalizing loyalty cards in tourism", in Fuchs, M., Ricci, F. and Cantoni, L. (eds.), Information and Comm. Tech. in Tourism, New York, Springer, pp 272-283.

Höpken, W., Fuchs, M., Keil, D., and Lexhagen, M. (2015), "Business intelligence for cross-process knowledge extraction at tourism destinations", Information Technology and Tourism, Vol. 15 No. 2, pp. 101-130.

Höpken., W., Ernesti, D., Fuchs, M., Kronenberg, K. and Lexhagen, M. (2017), "Big data as input for predicting tourist arrivals". In Schegg, R. \& Stangl, B. (eds.) Information and Communication Technologies in Tourism 2017, Springer, New York, 187-200.

Hsieh, K. (2011), "Employing a recommendation expert system based on mental accounting and artificial neural networks into mining business intelligence for study abroad' $\mathrm{s} \mathrm{P} / \mathrm{S}$ recommendations", Expert Systems with Applications, Vol. 38 No. 12, pp. 14376-14381.

Hsieh, K. (2009), "Applying an expert system into constructing customer's value expansion and prediction model based on AI techniques in leisure industry", Expert Systems with Applications, Vol. 36 No. 2 PART 2, pp. 2864-2872.

IBM (2012), "Analytics. The real world use of Big Data - How innovative enterprises extract value from uncertain data IBM Institute for Business Value". Retrieved June $27^{\text {th }}$ from http://www.informationweek.com/pdf_whitepapers/approved/1372892704_analytics_the_real_w orld_use_of_big_data.pdf .

Ip, C., Law, R. and Lee, H.A. (2011), "A review of website evaluation studies in the tourism and hospitality fields from 1996 to 2009”, International Journal of Tourism Research, Vol. 13 No. 3 , pp. 234-265.

Jackson, S. (2016), "Prediction, explanation and big(ger) data: A middle way to measuring and modelling the perceived success of a volunteer tourism sustainability campaign based on 'nudging", Current Issues in Tourism, Vol. 19 No. 7, pp. 643-658.

Jannach, D. (2016), "Big Data for Travel and Tourism Recommender Systems: A Position Statement", in Fuchs, M. Höpken, W. and Lexhagen (eds.), Big Data and Business Intelligence in the Travel and Tourism Industry, Östersund, Mid Sweden University, pp. 109-110.

Kasahara, H., Mori, M., Mukunoki, M., and Minoh, M. (2015), "Transportation mode annotation of tourist GPS trajectories under environmental constraints", in A. Inversini and R. Schegg (Eds.), Information and Communication Technologies in Tourism 2015, Heidelberg: Springer, pp. 523535.

Kimball, R., Ross, M., Thronthwaite, W., Mundy, J., and Becker, B. (2008), The data warehouse lifecycle toolkit ( $2^{\text {nd }}$ ed.), Indianapolis, Johne Wiley and Sons.

Kimball, R. and Ross, M. (2016), The Kimball group reader - Relentlessly practical tools for Data Warehsousing and Business Intelligence ( $2^{\text {nd }}$ ed.), Indianapolis, John Wiley and Sons.

Kirilenko, A.P., Stepchenkova, S. O., Kim, H. and Li, R. X. (2017), "Automated sentiment analysis in tourism: Comparison of approaches", Journal of Travel Research, doi/10.1177/0047287517729757

Kisilevich, S., Keim, D., and Rokach, L. (2013), “A GIS-based decision support system for hotel room rate estimation and temporal price prediction: The hotel brokers' context", Decision Support Systems, Vol. 54 No. 2, pp. 1119-1133.

Kitchin, R., and Lauriault, T. P. (2015), "Small data in the era of big data", GeoJournal, Vol. 80 No. 4, pp. 463-475. 
Klein, S. and Jacobs, J.A. (2016), "Position Statement on Big Data and Business Intelligence in Tourism", in Fuchs, M. Höpken, W. and Lexhagen (eds.), Big Data and Business Intelligence in the Travel and Tourism Industry, Östersund, Mid Sweden University, pp. 105-108.

Knudsen, C. (2003), "Pluralism, scientific progress, and the structure of organization theory", in H. Tsoukas and C. Knudsen (eds.), The Oxford Handbook of Organization Theory: Meta-Theoretical Perspectives, Oxford, Oxford University Press, pp. 262-286.

Kolas, N., Höpken, W., Fuchs, M. and Lexhagen, M. (2015), "Information gathering by ubiquitous services for CRM in tourism destinations", in Tussyadiah, I. and Inversini, A. (eds.), Information and Communication Technologies in Tourism, New York, Springer, pp. 73-85.

Kong, H. and Song, E. (2016), "A study on customer feedback of tourism service using social big data", Information (Japan), Vol. 19 No. 1, pp. 49-54.

Köseoglu, M. A., Ross, G., and Okumus, F. (2016), "Competitive intelligence practices in hotels", International Journal of Hospitality Management, Vol. 53, pp. 161-172.

Kwok, L., and Yu, B. (2016), "Taxonomy of facebook messages in business-to-consumer communications: What really works?" Tourism and Hospitality Research, Vol. 16 No. 4, pp. 311328.

Laney, D. (2001), “3D Data Management: Controlling Data Volume, Velocity and Variety”, META Group Research Note, 6. https://blogs.gartner.com/doug-laney/files/2012/01/ad949-3D-DataManagement-Controlling-Data-Volume-Velocity-and-Variety.pdf

Lam, C. and McKercher, B. (2013), "The tourism data gap: The utility of official tourism information for the hospitality and tourism industry", Tourism Management Perspectives, Vol. 6, pp. 82-94.

Larose, D. T. (2005), Discovering Knowledge in Data - An Introduction to Data Mining, New Jersey, John Wiley and Sons.

Law, R., Sun, S., Ka, D., Fong, C., Hoc, L., Fong, N., and Fu, H. (2016), "A systematic review of China's outbound tourism research", International Journal of Contemporary Hospitality Management, Vol. 28 No. 12, pp. 2654 - 2674.

Lazer, D. M., Kennedy, R., King, G., and Vespignani, A. (2014), “The parable of Google Flu: Traps in big data analysis", Science, Vol. 343 No. 14, pp. 1203-1205.

Leung, R., Rong, J., Li, G., and Law, R. (2013), "Personality differences and hotel web design study using targeted positive and negative association rule mining", Journal of Hospitality Marketing and Management, Vol. 22 No. 7, pp. 701-727.

Li G., Law R., Vu H.Q., Rong J., Zhao X. (2015, "Identifying emerging hotel preferences using Emerging Pattern Mining technique", Tourism Management, Vol. 46, pp. 311-321.

Liebowitz, J. (Ed.). (2013), Big data and business analytics, Boca Raton, FL, CRC Press.

Liu, F., Janssens, D., Wets, G. and Cools, M. (2013), “Annotating Mobile Phone Location Data with Activity Purposes using Machine Learning Algorithms”, Expert Systems with Applications, Vol. 40 No. 8: pp. 3299-3311.

Lu, W. and Stepchenkova, S. (2015), "User-generated content as a research mode in tourism and hospitality applications: Topics, methods, and software", Journal of Hospitality Marketing and Management, Vol. 24 No. 2, pp. 119-154.

Lu, Y. and Zhang, L. (2015), "Imputing trip purposes for long-distance travel”, Transportation, Vol. 42 No. 4, pp. 581-595.

Luhn, H.P. (1958), “A Business Intelligence System”, IBM Journal, Vol. 2 No. 4, pp. 314-319.

Lycett, M. (2013), “Datafication': Making sense of (big) data in a complex world”, European Journal of Information Systems, Vol. 22, pp. 381-386.

Mariani, M.M. and Borghi, M. (2018), "Effects of the Booking.com rating system: Bringing hotel class into the picture", Tourism Management, Vol. 66, 47-52.

Mariani, M. M., Di Felice, M., and Mura, M. (2016), "Facebook as a destination marketing tool: Evidence from Italian regional Destination Management Organizations", Tourism Management, Vol. 54, pp. 321-343. 
Mariani, M.M., Buhalis, D., Czakon, W., and Vitouladiti, O. (2016), Tourism Management, Marketing, and Development. Performance, Strategies, and Sustainability, New York, PalgraveMacmillan.

Marine-Roig, E. and Anton Clavé, S.A. (2015), "Tourism analytics with massive user-generated content: A case study of Barcelona", Journal of Destination Marketing and Management, Vol. 4 No. 3, pp. 162-172.

Mayer-Schönberger, V., and Cukier, K. (2013), Big data: A revolution that will transform how we live, work, and think. New York: Houghton Mifflin Harcourt.

McAfee, A., Brynjolfsson, E., Davenport, T. H., Patil, D. J., and Barton, D. (2012), "Big Data. The management revolution", Harvard Business Review, Vol. 90 No. 10, pp. 61-67.

McFarland, D. A., and McFarland, H. R. (2015), "Big Data and the danger of being precisely inaccurate", Big Data and Society, Vol. 2 No. 2, pp. 1-4.

Menner, T., Höpken, W., Fuchs, M., and Lexhagen, M. (2016), "Topic detection - Identifying relevant topics, within touristic UGC", in A. Inversini and R. Schegg (Eds.), Information and Communication Technologies in Tourism 2015, Heidelberg: Springer, pp. 411-423.

Mi, C., Shan, X., Qiang, Y., Stephanie, Y., and Chen, Y. (2014), "A new method for evaluating tour online review based on grey 2-tuple linguistic”, Kybernetes, Vol. 43 No. 3, pp. 601-613.

Mitchell, T. M. (1997), Machine Learning, New York, McGraw Hill.

Mocanu, D., Baronchelli, A., Perra, N., Gonçalves, B., Zhang, Q., and Vespignani, A. (2013), “The twitter of babel: Mapping world languages through microblogging platforms", PLoS ONE, Vol. 8 No. 4, doi:10.1371/journal.pone.0061981

Noguchi, K., Sato, Y., and Shiohara, H. (2016), "Advanced, high-performance big data technology and trial validation", NTT Technical Review, Vol. 14 No. 2, pp 1-7.

Önder, I., Koerbitz, W., and Hubmann-Haidvogel, A. (2014), "Tracing Tourists by Their Digital Footprints The Case of Austria", Journal of Travel Research, Vol. 55 No. 5, pp. 566-573, doi: $10.1177 / 0047287514563985$.

Orellana, D., Bregt, A. K., Ligtenberg, A., and Wachowicz, M. (2012), "Exploring visitor movement patterns in natural recreational areas", Tourism Management, Vol. 33 No. 3, pp. 672- 682.

Paldino, S., Bojic, I., Sobolevsky, S., Ratti, C., and González, M. C. (2015), "Urban magnetism through the lens of geo-tagged photography", EPJ Data Science, Vol. 4 No. 1, pp. 1-17.

Park, S. B., Ok, C. M., and Chae, B. K. (2015), "Using Twitter Data for Cruise Tourism Marketing and Research", Journal of Travel and Tourism Marketing, doi: 10.1080/10548408.10542015.11071688.

Pope, S., Garrow, L., Guin, A., Leonard, J., Bankston, L., and Campbell, P. (2009), "Conceptual framework for collecting online airline pricing data: Challenges, opportunities, and preliminary results", Transportation Research Record: Journal of the Transportation Research Board, Vol. 2106, pp. 30-37.

Power, D. J. (2014), “Using 'Big Data' for analytics and decision support”, Journal of Decision Systems, Vol. 23 No. 2, pp. 222-228.

Power, D. J. (2007), A Brief History of Decision Support Systems, version 4.0, retrieved 6 June 2017, DSS-Resources.com.

Prayag, G., Hosany, S. and Odeh, K. (2013), "The role of tourists' emotional experiences and satisfaction in understanding behavioral intentions", Journal of Destination Marketing and Management, Vol. 2 No. 2, pp. 118-127.

Pyle, D. (1999), Data Preparation for data mining, Oxford, Morgan Kaufmann.

Qiao, X., Zhang, L., Li, N., and Zhu, W. (2014), "Constructing a Data Warehouse Based Decision Support Platform for China Tourism Industry”, in Z. Xiang and I. Tussyadiah (Eds.), Information and Communication Technologies in Tourism 2014, Heidelberg, Springer, pp. 883-893.

Raun, J., Ahas, R., and Tiru, M. (2016), "Measuring tourism destinations using mobile tracking data", Tourism Management, Vol. 57, pp. 202-212. 
Ritchie, R.J. and Ritchie, J.B. (2002), “A framework for an industry supported destination marketing information system", Tourism Management, Vol. 23 No. 5, pp. 439-454.

RocaSalvatella. (2014), Big Data and Tourism: New Indicators for Tourism Management. Barcelona: Telefónica I+D and RocaSalvatella. Retrieved September, 2015, from http://www.rocasalvatella.com/sites/default/files/big_data_y_turismo-eng-interactivo.pdf.

Rossetti, M., Stella, F. and Zanker, M. (2016), "Analyzing user reviews in tourism with topic models", Information Technology and Tourism, Vol. 16 No. 1 pp. 5-21.

Rud, O. (2009), Business Intelligence Success Factors: Tools for Aligning Your Business in the Global Economy, N.J: Wiley and Sons.

Russell, M. A. (2013), Mining the Social Web: Data Mining Facebook, Twitter, LinkedIn, Google+, GitHub, and More, Sebastopol, CA, O'Reilly Media Inc.

Sánchez-Franco M.J., Navarro-García A., and Rondán-Cataluña F.J. (2016), “Online customer service reviews in urban hotels: A data mining approach", Psychology \& Marketing, 33(12), 1174-1186.

Sauter, V. (2011), Decision Support Systems for Business Intelligence ( $2^{\text {nd }}$ edition), New Jersey, John Wiley and Sons.

Schmunk, S., Höpken, W., Fuchs, M., and Lexhagen, M. (2014), "Sentiment Analysis Implementation and Evaluation of Methods for Sentiment Analysis with Rapid-Miner ${ }^{\circledR}$ ", in Z. Xiang and I. Tussyadiah (Eds.), Information and Communication Technologies in Tourism 2014, Heidelberg, Springer, pp. 253-265.

Shi, M, Zhu, W, Yang, H and Li, C. (2016), “Applying semantic web and big data techniques to construct a balance model referring to stakeholders of tourism intangible cultural heritage", International Journal of Computer Applications in Technology, Vol. 54 No. 3, pp. 192200.

Shoval, N. and Isaacson, M. (2010), Tourist mobility and advanced tracking technologies, New York: Routledge.

Shoval, N., Schvimer, Y. and Tamir, M. (2018). "Real-time measurement of tourists' objective and subjective emotions in time and space", Journal of Travel Research, Vol. 57, No. 1, pp. 3-16.

Sinisalo, J., Salo, J., Karjaluoto, H. and Leppäniemi, M. (2007), "Mobile customer relationship management: underlying issues and challenges", Business Process Management Journal, Vol. 13 No. 6, pp. 771- 787.

Snavely, N., Seitz, S. M., and Szeliski, R. (2008), "Modelling the world from internet photo collections", International Journal of Computer Vision, Vol. 80 No. 2, pp. 189-210.

Solnet D., Boztug Y., and Dolnicar S. (2016), "An untapped gold mine? Exploring the potential of market basket analysis to grow hotel revenue", International Journal of Hospitality Management, Vol. 56 No. 3, 119-125.

Su, S., Wan, C., Hu, Y., and Cai, Z. (2016), "Characterizing geographical preferences of international tourists and the local influential factors in china using geo-tagged photos on social media", Applied Geography, Vol. 73, pp. 26-37.

Sun, P., Cárdenas D.A., and Harrill R. (2016), "Chinese Customers' Evaluation of Travel Website Quality: A Decision-Tree Analysis", Journal of Hospitality Marketing and Management, Vol. 25 No. 4, pp. 476-497.

Sun, Y., Song, H., Jara, A. J., and Bie, R. (2016), "Internet of things and big data analytics for smart and connected communities" IEEE Access, Vol. 4, pp. 766-773.

Supak, S., Brothers, G., Bohnenstiehl, D., and Devine, H. (2015), "Geospatial analytics for federally managed tourism destinations and their demand markets", Journal of Destination Marketing and Management, Vol. 4 No. 3, pp. 173-186.

Tang, J., and Li, J. (2016), "Spatial network of urban tourist flow in Xi' an based on microblog big data", Journal of China Tourism Research, Vol. 12 No. 1, pp. 5-23. 
Tranfeld, D., Denyer, D. and Smart, P. (2003), "Towards a methodology for developing evidenceinformed management knowledge by means of systematic review", British Journal of Management, Vol. 14, pp. 207-222.

Tseng, S. and Won, Y. (2016), "Integrating multiple recommendation schemes for designing sales force support system: A travel agency example", International Journal of Electronic Business, Vol. 13 No. 1, pp. 1-37.

Vieira, E. S., and Gomes, J.A.N.F. (2009), “A comparison of Scopus and Web of Science for a typical university”, Scientometrics, Vol. 81 No. 2, pp. 587-600.

Verhoef, P.C., Kooge, E., and Walk, N., (2016), Creating Value with Big Data Analytics: Making Smarter Marketing Decisions, London, Routledge.

Versichele M., de Groote L., Claeys Bouuaert M., Neutens T., Moerman I., and Van de Weghe N. (2014), "Pattern mining in tourist attraction visits through association rule learning on Bluetooth tracking data: A case study of Ghent, Belgium", Tourism Management, Vol. 44, pp. 67-81.

Vogt, C. (2011), “Customer Relationship Management in Tourism”, Journal of Travel Research, Vol. 50 No. 4, pp. 356-364.

Wang, X. L., Yoonjoung Heo, C., Schwartz, Z., Legohérel, P., and Specklin, F. (2015), "Revenue management: progress, challenges, and research prospects", Journal of Travel and Tourism Marketing, Vol. 32 No. 7, pp. 797-811.

Wang, D., Park, S. and Fesenmaier, D.R. (2012), "The Role of Smartphones in Mediating the Touristic Experience", Journal of Travel Research, Vol. 51 No. 4, pp. 371-387.

White, T. (2015), Hadoop: The Definitive Guide, 4th Edition - Storage and Analysis at Internet Scale, Sebastopol, CA: O'Reilly Media.

Williams, S. (2016), Business Intelligence Strategy and Big Data Analytics, Cambridge (MA), Morgan Kaufmann.

Witten, I. H., Frank, E., Hall, M. A., and Pal, C. J. (2016), Data Mining: Practical machine learning tools and techniques, Cambridge (MA): Morgan Kauffman.

Wood, S. A., Guerry, A. D., Silver, J. M., and Lacayo, M. (2013), "Using social media to quantify nature-based tourism and recreation", Scientific Reports, 3 doi:10.1038/srep02976

Wu, E.H.C., Law R., and Jiang B. (2010), "Data mining for hotel occupancy rate: An independent component analysis approach", Journal of Travel and Tourism Marketing, Vol. 27 No.4, pp. 426-438.

Xiang, Z., Schwartz, Z., Gerdes, J. H., and Uysal, M. (2015), "What can big data and text analytics tell us about hotel guest experience and satisfaction?", International Journal of Hospitality Management, Vol. 44, pp. 120-130.

Xiang, Z. (2016), "Analytics for Tourism Management: Needs and Directions for Research", in Fuchs, M. Höpken, W. and Lexhagen (eds.), Big Data and Business Intelligence in the Travel and Tourism Industry, Östersund, Mid Sweden University, pp. 127-131.

Xiang, Z. (2018), "From digitization to the age of acceleration: On information technology and tourism", Tourism Management Perspectives, doi.org/10.1016/j.tmp.2017.11.023

Yang, Y., Pan, B., and Song, H. (2014), "Predicting hotel demand using destination marketing organization's web traffic data”, Journal of Travel Research, Vol. 53 No. 4, pp. 433-447.

Yuan, Y. L., and Ho, C. I. (2015), "Rethinking the Destination Marketing Organization Management in the Big Data Era", in Proceedings of the ASE Big Data and Social Informatics 2015, ACM, p. 60 .

Zanker, M, Jessenitschnig, M. and Fuchs, M. (2010), “Automated Semantic Annotation of Tourism Resources based on Geo-Spatial Data", Information Technology and Tourism, Vol. 11 No. 4: pp. 341-354.

Zhang C., and Huang Z. (2015), "Mining tourist motive for marketing development via twicelearning", Applied Artificial Intelligence, Vol. 29 No. 2, pp. 119-132.

Zhu Z., Shou L., and Chen K. (2016). "Get into the spirit of a location by mining user-generated travelogues", Neurocomputing, Vol. 204, pp. 61-69. 
